Ernesto Fernando Rodrigues Vicente ${ }^{1}$ Enivaldo de Oliveira Scheffer ${ }^{2}$

* Recebido em: 05/06/2013

Aprovado em: 06/11/2013

1 Doutor em Administração, Mestre em Contabilidade e Bacharel em Ciências Contábeis pela Universidade de São Paulo. Atualmente é Professor Adjunto do Departamento de Ciências Contábeis, do Centro Sócio-Econômico, da Universidade Federal de Santa Catarina (CCN/ CSE/UFSC), tendo sido Sócio-Diretor da TECHTI-Tecnologia da Informação Comércio e Serviços. Tem publicado trabalhos em Anais de Eventos, periódicos e orientado diversos trabalhos de graduação, de iniciação científica e de pós-graduação em cursos de Contabilidade e de Administração. Governança nas Organizações, Administração \& Administração Financeira, Custos, ERP, Contabilidade \& Controladoria são as minhas áreas de atuação.

2 Especialista em Controle da Gestão Pública Municipal pela Universidade Federal de Santa Catarina - UFSC e em Ciência da Computação pela Universidade Federal do Rio Grande do Sul - UFRGS e graduado em Processamento de Dados pela Universidade Luterana do Brasil - ULBRA. Atualmente é Analista de Sistemas na Secretaria de Tecnologia de Informação e Comunicação, da Universidade do Estado de Santa Catarina - UDESC, com experiência em gerencia de projetos de TI, analise e desenvolvimento de sistemas.

\section{Governança e Internet: um estudo de caso sobre a divulgação de dados da Administração Pública sob a ótica dos princípios da governança pública*}

\section{Governance and the Internet: a case study on the disclosure of data of public administration from the perspective of the principles of public governance}

\section{Resumo}

Este estudo tem como objetivo identificar o nível de divulgação dos dados da Administração Pública sob a ótica dos princípios da governança pública. Assim, a presente pesquisa tem como questão o problema: os dados da Administração Pública divulgados na internet atendem aos princípios da governança pública? Para atingir os objetivos foram utilizados procedimentos técnicos da pesquisa bibliográfica, da pesquisa documental e do estudo de caso. Quanto à abordagem do problema, a pesquisa é classificada como qualitativa e quantitativa: como exploratória e descritiva quanto aos objetivos, e de natureza aplicada. Por meio de pesquisa exploratória, foram analisadas as informações disponíveis nos websites dos municípios da microrregião de Florianópolis. Para medir o nível de divulgação dos dados, construiu-se um quadro composto por dez grupos de informação. O quadro foi construído a partir de pesquisa bibliográfica sobre a governança pública e a divulgação dos dados no setor público. Com base neste quadro, e aplicando uma escala de valores, foram observados os dados disponíveis nos websites oficiais dos municípios pesquisados. A escala de valores possui dois grupos e mensura a informação disponível e a interação, assumindo valores de 1 a 5 . A pesquisa foi realizada no mês de janeiro de 2012, e como resultado, constatou-se que o nível médio de divulgação da governança nos municípios pesquisados foi de 3 , isto é, apresentou uma disponibilidade dos dados entre 26 a 50 por cento.

Palavras-chave: Governança. Internet. Administração Pública. Transparência. Gestão pública.

\begin{abstract}
This study aims to identify the level of disclosure of the data of the public administration from the perspective of the principles of public governance. Thus, this research has as a matter of problem: the public administration data disclosed on the internet meet the principles of public governance? To achieve the goals were used technical procedures of bibliographical research, desk research and case study. How to approach the problem, the research is classified as exploratory, qualitative and quantitative and descriptive as to goals, and of applied nature. Through exploratory research, analyzed
\end{abstract}


the information available on the websites of municipalities in the region of Florianópolis. To measure the level of dissemination of data built up a framework composed of 10 groups of information. The frame was constructed from bibliographical research on governance and public dissemination of data on the public sector. Based on this framework and applying a range of values were observed data available on the official websites of the municipalities researched. The scale of values has 2 groups and measures the available information and interaction, assuming 1 to 5 values. The survey was conducted in January 2012, and as a result, it was found that the average level of disclosure of governance in the municipalities surveyed was 3 , that is, presented a data availability between 26 to 50 percent.

Keywords: Governance. Internet. Public Administration. Transparency. Public management.

\section{Introdução}

O setor público vem sofrendo um complexo processo de reforma em sua estrutura, situação que requer adaptação contínua às mudanças ambientais e de ajustamento às pessoas, às leis e à sociedade. A busca de mecanismos capazes de lidar com essa nova realidade e desenvolver processos institucionais que promovam maior estímulo à eficiência, à produtividade, à transparência, à prestação de contas e à participação efetiva de cada cidadão na gestão pública é busca constante na Administração Pública moderna e um dos grandes desafios do setor público na atualidade. Essa nova realidade social, a necessidade de modernização e inovação na gestão pública, deu origem a um novo estilo de governar, que muitos autores definem como Governança Pública ou como Governança.

A Governança Pública está associada à mudança na gestão, que passa a ser orientada para as formas de interação nas relações de poder entre o Estado, o governo e a sociedade, dedicando especial atenção aos processos de cooperação e de interação, aos mecanismos que estimulam as relações entre os principais atores envolvidos nesse esforço, buscando construir um ambiente sustentável para todos. Logo, se governança é construída a partir da participação crescente da sociedade, num processo de interação nas decisões e nas formulações estratégicas, então é fundamental que todos os agentes interessados tenham acesso à informação, entendam os processos e participem efetivamente na gestão do município.
A sociedade vive na era da informação e a internet tem um papel importante nessa nova sociedade. Globalizada e interativa, ela modifica a forma com que as pessoas, empresas e governos se relacionam, trazendo novas perspectivas para a democracia e introduzindo na sociedade uma nova forma de comunicação, na qual cada cidadão pode ser um agente transformador da realidade. Numa sociedade em que a informação é a matéria-prima para muitas áreas do conhecimento, fonte de capital e de poder, a internet é uma ferramenta indispensável no processo de democratização da informação, essencial para o controle democrático, para a participação popular e para efetividade da governança no setor público.

A sociedade brasileira tem a necessidade crescente de acompanhar de perto o processo de gestão da Administração Pública, começando pela mais próxima, a municipal, permitindo uma participação efetiva no que ocorre no município, de modo a permitir a avaliação de seu desempenho, o uso dos recursos públicos, a corrupção e a ineficiência dos controles. Nesse contexto, é importante que existam mecanismos capazes de oferecer à sociedade ferramentas que possibilitem o acesso irrestrito às informações públicas e que permitam uma interação eficiente de tal modo que possa alterar o curso da ação administrativa. Para que a sociedade civil, empresas e demais interessados possam participar efetivamente na gestão do município, é fundamental que os dados governamentais sejam disponibilizados num ambiente de comunicação de massa, interativo, instantâneo e multimídia como a internet.

A pesquisa tem como questão-problema saber se os dados da Administração Pública divulgados na internet atendem aos princípios da Governança Pública? É nesse contexto que tal estudo se desenvolve e tem como objetivo identificar o nível de divulgação dos dados da Administração Pública sob a ótica dos princípios da Governança Pública.

Essa pesquisa contribui para melhorar a transparência da ação administrativa na esfera municipal, para o desenvolvimento de processos e ferramentas tecnológicas e de gestão da informação que possam melhorar a interação entre a sociedade, o governo e o Estado, bem como entender melhor as necessidades de informações no processo de interação, premissas essenciais para efetividade da governança no setor público. 
Esse trabalho é relevante porque busca aumentar o conhecimento a respeito da divulgação das estruturas de governança na esfera municipal. Nesse sentido, a divulgação contribui para diminuir a assimetria informacional entre gestores e as partes interessadas nas práticas de gestão no setor público.

\section{Referencial Teórico}

\subsection{Governança Pública}

O setor público vem sofrendo um complexo processo de reforma em sua estrutura, situação essa que requer adaptação contínua às mudanças ambientais e de ajustamento às pessoas, às leis e à sociedade, refletindo na incapacidade do Estado em atender as demandas públicas sociais locais e de lidar com os mecanismos legais que vêm instituindo novas formas de interação nas relações de poder entre o Estado, o governo e a sociedade. Dessa necessidade de modernização e inovação na gestão, emergiu um novo estilo governamental - o que Diniz (1996), chama de Governança Pública.

Segundo Kissler e Heidemann (2006), a Governança Pública é um novo modelo que surgiu devido às condições insatisfatórias da modernização praticada até o momento. O modelo conceitua-se como uma nova geração de reformas administrativas e de Estado, que tem como objeto a ação conjunta levada a efeito de forma eficaz, transparente e compartilhada, pelo Estado, pelas empresas e pela sociedade, visando uma solução inovadora dos problemas sociais e criando possibilidades e chances de um desenvolvimento sustentável para todos os participantes.

Para Skickert (1997 apud VIANA, 2010), a Governança Pública tem um significado mais amplo do que o conceito de administração usual e limitado, encontrado nos negócios e na interpretação orientada para o mercado. Governança também abrange a legalidade e a legitimidade dos atos da organização, e a interação entre o contexto público e o social representa um papel crucial no processo. Assim, a Governança no setor público é um complexo de princípios e atividades, envolvendo a direção do gerenciamento no setor público da sociedade. Não se trata somente do aumento da efetividade e eficiência, mas também de guardar a legalidade e legitimidade.

Ainda sobre a abrangência da governança, Santos (1997), enfatiza que ela não se limita apenas a aspectos gerenciais e administrativos do Estado, e tampouco ao funcionamento eficaz de seu aparelho. Governança Pública refere-se a "[...] padrões de articulação e cooperação entre atores sociais e políticos e arranjos institucionais que coordenam e regulam transações dentro e através das fronteiras do sistema econômico". Inclui-se ai “[...] não apenas os mecanismos tradicionais de agregação e articulação de interesses, tais como os partidos políticos e grupos de pressão, como também redes sociais e associações de diversos tipos".

Segundo Kaufmann (2002 apud STREIT, 2006), a transparência é um componente da governança de grande importância. Ela diz respeito ao fluxo confiável e tempestivo de informações políticas, econômicas e sociais que estão disponíveis a todos os interessados. A transparência deve compreender o acesso à informação pelo cidadão e o entendimento do processo decisório da organização de modo a permitir base sólida para accountability, para verificar a má gestão e irregularidades, melhorar a confiança do cidadão e a participação "informada" pelo mesmo.

Princípios e melhores práticas de Governança Corporativa Slomski (2009, p. 132):

Os princípios básicos que inspiram o código das melhores práticas de governança corporativa são: (a) a transparência; (b) a equidade; (c) a prestação de contas; e $(\mathrm{d})$ a responsabilidade corporativa. Todos esses princípios são aplicáveis às entidades públicas governamentais.

Para o Instituto Brasileiro de Governança Corporativa (IBGC) (2011), os princípios de Governança Corporativa são: a) transparência: mais do que a "obrigação de informar", a administração deve cultivar o "desejo de informar"; b) equidade: tratamento justo e igualitário de todos os grupos minoritários, sejam os acionistas, sejam as demais partes interessadas; não são aceitas atitudes ou políticas discriminatórias; c) prestação de contas com responsabilidade (accountability): os agentes de governança devem prestar contas a quem os elegeu e responder por todos os atos que praticarem durante sua gestão; e d) responsabilidade corporativa: os conselheiros e executivos devem zelar pela visão de longo prazo e sustentabilidade da organização e incorporar assuntos de ordem social e ambiental na definição dos negócios e operações.

A Lei Complementar n. ${ }^{\circ}$ 101/2000, conhecida com Lei de Responsabilidade Fiscal, estabeleceu o primeiro marco regulatório, definindo alguns princípios de 
Governança Pública como: a) equilíbrio fiscal, baseado na compatibilização das despesas com as receitas; b) limitação de gastos com pessoal; c) regulamentação da renúncia de receita ou concessão de benefícios tributários; d) limite de endividamento público; e) eficiência na gestão patrimonial e das despesas públicas; e f) maior transparência com a criação de relatórios de gestão publicados periodicamente.

A Figura 1 representa o modelo de governança que deve ser buscado pela Administração Pública local. A Governança Pública, no âmbito municipal, deve promover um ambiente social de diálogo e de cooperação, com alto nível de democracia, de conectividade e de interação, mediante ações que estimulem a constituição de parcerias entre todos os setores da sociedade a fim de construir consensos que tornem possível formular políticas públicas que respondam equilibradamente ao que a sociedade espera do governo.

Figura 1 - representação da Governança Pública Municipal

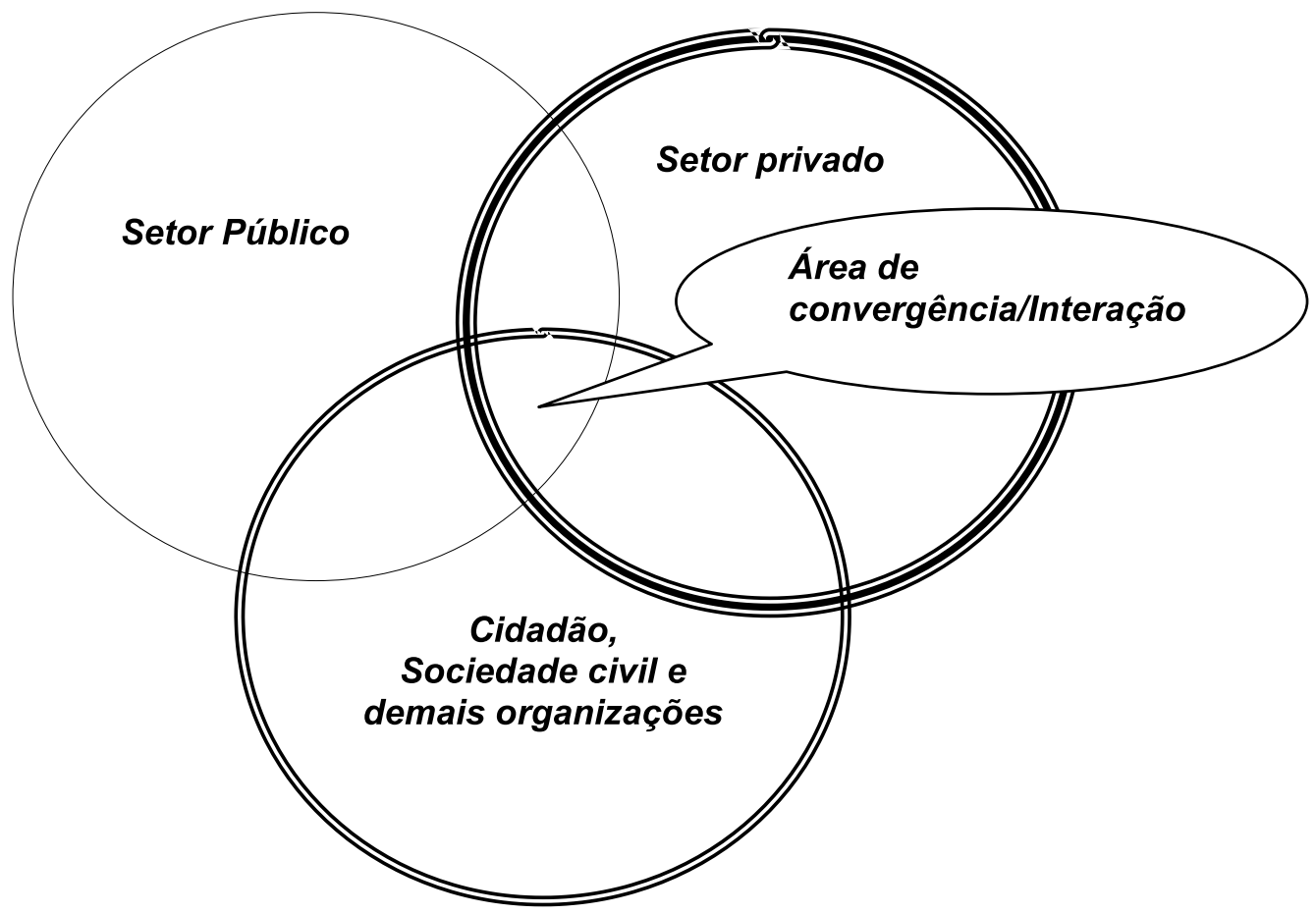

Fonte: Adaptado de Skickert (1997 apud VIANA, 2010); Santos (1997); Kissler e Heidemann (2006)

\subsection{A Internet e a sociedade da informação}

A sociedade passa por uma revolução com o surgimento de um novo meio de comunicação, o mais abrangente já desenvolvido pelo homem: a internet, aldeia repleta de possibilidades e caminhos, onde qualquer indivíduo é ao mesmo tempo emissor e receptor da informação, podendo interagir de forma até então inexistente na sociedade. Com o surgimento desse novo meio, diversos paradigmas começam a ser modificados e nossa sociedade depara-se com uma nova revolução, uma sociedade que tem como insumo básico a informação.

Para Castells (2003), a sociedade atual está construída em torno de fluxos: de capital, de informação, de tecnologia, os quais expressam os processos da vida social em suas diversas facetas.
[...] há uma nova forma espacial característica das práticas sociais que dominam e moldam a sociedade em rede: o espaço de fluxos. [...] Por fluxos entendo as consequências intencionais, repetitivas e programáveis de intercâmbio e interação entre posições fisicamente desarticuladas, mantidas por atores sociais nas estruturas econômica, política e simbólica da sociedade. (CASTELLS, 2003, p. 501).

A internet carrega ampla variedade de recursos e serviços. Esse ambiente denominado ciberespaço, mundo virtual ou simplesmente rede, fez emergir uma nova ordem mundial, modificando as relações entre as pessoas, as empresas e os governos: um mundo sem limites territoriais, onde cada um pode interagir, consumindo e produzindo informação. Tal interação traz novas perspectivas para um futuro democrático para humanidade (PIERRE LÉVY, 1997). 
Numa sociedade baseada na informação, o governo deve promover a universalização do acesso à informação e o uso crescente dos meios eletrônicos a fim de construir uma administração eficiente e transparente em todos os níveis. Saliente-se ainda que a administração deve ser centrada no cidadão, no governo ao alcance de todos e voltada para prestação de informações e serviços à população. A possibilidade de acesso aos serviços, de participação nas decisões e de acompanhamento dos atos governamentais por parte de todos os cidadãos impõe a adoção de meios e métodos digitais, em todos os poderes constituídos e níveis governamentais, com o emprego das tecnologias de informação e de comunicação em benefício da eficácia, da responsabilidade, da transparência e da Governança Pública (TAKAHASHI et al., 2000).

O surgimento da internet trouxe novos elementos para o cenário dos meios de comunicação, permitiu a reconfiguração do nosso sistema de pensamento, e mais: mudou nossa ideia de comunicação, base da nossa sociedade além de trazer possibilidades nunca antes imaginadas no sentido da democratização da informação. Convergiu as mídias num ambiente único, introduziu a interatividade, que se caracteriza por relações interdependentes e processos de negociação, no qual cada interagente participa da construção inventiva da interação, afetando-se mutuamente. Enfim, a rede oferece a cada cidadão a perspectiva de atuar como agente transformador da realidade e mudar o curso das coisas. Como meio de comunicação, fez acontecer a Sociedade da Informação, imaginada e criticada por pensadores como Castells (1999).

$\mathrm{Na}$ sociedade atual, a informação passa a constituir a matéria-prima para diversas áreas do conhecimento, fonte não apenas de capital, mas também de poder. Baseada na informação, a internet passa a ter um papel central, tanto em termos de circulação de capital, na reconfiguração do espaço e das relações sociais, bem como no equilíbrio de poder, e altera a forma das relações entre os cidadãos, empresas e governos. Tal espaço é visto como o cerne para democracia, como ferramenta essencial para transparência da ação administrativa dos governos, para a participação popular e para o controle democrático, premissas fundamentais que visam concretizar a governança no setor público.

\subsection{Divulgação de dados no setor público}

Conforme estabelece o artigo 48 da Lei Complementar 101/2000, a transparência dos dados na Administração Pública está associada à confiabilidade, à relevância e à compreensibilidade das informações prestadas.

[...] dispõe que são instrumentos de transparência da gestão fiscal, aos quais será dada ampla divulgação, inclusive em meios eletrônicos de acesso público: os planos, orçamentos e leis de diretrizes orçamentárias; as prestações de contas e os respectivos pareceres prévios; o Relatório Resumido da Execução Orçamentária e o Relatório de Gestão Fiscal, e as versões simplificadas desses documentos [...]. (BRASIL, 2000)

O direito de acesso à informação é garantido pela Constituição Federal de 1988, nos artigos 5, $37^{\circ}$ e $216^{\circ}$ :

Artigo $5^{\circ}$ - XXXIII - todos têm direito a receber dos órgãos públicos informações de seu interesse particular, ou de interesse coletivo ou geral, que serão prestadas no prazo da lei, sob pena de responsabilidade, ressalvadas aquelas cujo sigilo seja imprescindível à segurança da sociedade e do Estado.

Artigo 37 - A administração pública direta e indireta de qualquer dos Poderes da União, dos Estados, do Distrito Federal e dos Municípios obedecerá aos princípios de legalidade, impessoalidade, moralidade, publicidade e eficiência [...].

$\$ 3^{\circ}$ A lei disciplinará as formas de participação do usuário na administração pública direta e indireta, regulando especialmente:

II - o acesso dos usuários a registros administrativos e a informações sobre atos de governo

Artigo 216 - $\$ 2^{\circ}$ Cabem à administração pública, na forma da lei, a gestão da documentação governamental e as providências para franquear sua consulta a quantos dela necessitem.

Em novembro de 2011 foi aprovada a Lei 12.527/2011, que regulamenta o acesso às informações previstas na Constituição Federal, garantindo o direito à informação e obrigando os órgãos públicos a considerarem a publicidade como regra e o sigilo como exceção. A referida Lei se estende ainda às organizações de qualquer natureza que recebam recursos públicos. Com a promulgação dessa Lei, a divulgação de informações de interesse público ganha procedimentos para facilitar e agilizar o acesso a tais dados por qualquer pessoa, inclusive com o uso da tecnologia da informação, e para fomentar o desenvolvimento de uma cultura de transparência e de con- 
trole social na Administração Pública. Conforme $\$ 4^{\circ}$, do artigo $8^{\circ}$ da referida Lei, estão desobrigados de divulgar os dados na internet apenas os municípios como até 10 mil habitantes.

$\$ 4^{\circ}$ Os Municípios com população de até 10.000 (dez mil) habitantes ficam dispensados da divulgação obrigatória na internet a que se refere o $\$ 2{ }^{\circ}$, mantida a obrigatoriedade de divulgação, em tempo real, de informações relativas à execução orçamentária e financeira, nos critérios e prazos previstos no art. 73-B da Lei Complementar $n^{\circ} 101$, de 4 de maio de 2000 (Lei de Responsabilidade Fiscal). (BRASIL, 2011)

O Estado tem a obrigação de disponibilizar as informações públicas, conforme artigos $5^{\circ}$ e $8^{\circ}$ da Lei 12.527/2011:

Art. $5^{\circ}$ É dever do Estado garantir o direito de acesso à informação, que será franqueada, mediante procedimentos objetivos e ágeis, de forma transparente, clara e em linguagem de fácil compreensão.

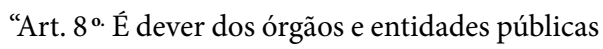
promover, independentemente de requerimentos, a divulgação em local de fácil acesso, no âmbito de suas competências, de informações de interesse coletivo ou geral por eles produzidas ou custodiadas.

Para Sant'ana (2009), a divulgação de informações oriundas da Administração Pública não deve se restringir apenas ao controle de improbidades e a procedimentos de corrupção, mas também na possibilidade de permitir que agentes públicos e cidadãos possam discutir de forma ampla e aberta os rumos a serem tomados pelo município em todos os aspectos.

\section{Metodologia}

A pesquisa é de natureza aplicada. Referindo-se à abordagem do problema, o estudo é classificado como

Quadro1 - Lista de municípios da microrregião de Florianópolis qualitativo e quantitativo, e quanto aos objetivos, é uma pesquisa exploratória e descritiva. Para atingir os objetivos, foram utilizados procedimentos da pesquisa bibliográfica, da pesquisa documental e do estudo de caso.

Conforme Silva e Menezes (2001), a pesquisa aplicada tem como objetivo gerar conhecimentos para aplicação prática, dirigidos à solução de problemas específicos. A pesquisa descritiva tem como objetivo principal a análise e a descrição de características de determinado tema, feitas por meio de coletas de informações, seja por questionários ou por observações (FIGUEIREDO, 2004). $\mathrm{Na}$ pesquisa descritiva, procura-se conhecer a realidade estudada, suas características e seus problemas. Já a pesquisa exploratória, de acordo com Gil (2002), visa indagar o pesquisador e tem como objetivo responder ao problema da pesquisa, bem como o aprimoramento de ideias.

O estudo de caso consiste no estudo profundo e exaustivo de um ou poucos objetos, de maneira que permita seu amplo e detalhado conhecimento. Segundo Raupp e Beuren (2009), é um procedimento predominante nas pesquisas em que se deseja aprofundar conhecimento a respeito de uma situação específica.

Foi realizada uma revisão de literatura para sintetizar o conhecimento e dar suporte para abordagem do problema. A revisão buscou subsídios sobre a divulgação dos dados no setor público, a internet na sociedade atual e sobre Governança Pública, com foco nos princípios de governança aplicados ao setor público.

$\mathrm{O}$ universo da pesquisa abrange os municípios pertencentes à microrregião de Florianópolis, conforme Quadro 1, e foi realizada no período de 16 a 21 de janeiro de 2012, por meio da observação dos dados sobre governança, disponíveis nos websites oficiais dos municípios pesquisados.

\begin{tabular}{c|c|c|c}
\hline Município & Website & $\begin{array}{c}\text { Área } \\
\text { (km2) }\end{array}$ & \begin{tabular}{c} 
População \\
\hline Antônio Carlos
\end{tabular} \\
\hline Biguaçu & www.antoniocarlos.sc.gov.br & 229.118 & 7.455 \\
\hline Florianópolis & www.bigua.sc.gov.br & 324.521 & 58.238 \\
\hline $\begin{array}{c}\text { Governador Celso } \\
\text { Ramos }\end{array}$ & www.pmf.sc.gov.br & 433.317 & 421.203 \\
\hline Palhoça & www.governadorcelsoramos.sc.gov.br & 93.061 & 13.012 \\
\hline Paulo Lopes & www.palhoca.sc.gov.br & 394.662 & 137.199 \\
\hline $\begin{array}{c}\text { Santo Amaro da } \\
\text { Imperatriz }\end{array}$ & www.paulolopes.sc.gov.br & 450.372 & 6.692 \\
\hline
\end{tabular}




\begin{tabular}{c|c|c|c}
\hline Município & Website & $\begin{array}{c}\text { Área } \\
(\mathbf{k m 2})\end{array}$ & \begin{tabular}{c} 
População \\
\hline São José
\end{tabular} \\
\hline $\begin{array}{c}\text { São Pedro de } \\
\text { Alcântara }\end{array}$ & www.pmsj.sc.gov.br & 113.171 & 210.513 \\
\hline
\end{tabular}

Fonte: Adaptado de IBGE (2011).

Com base nos princípios da Governança Pública e da divulgação dos dados do setor público, foram definidos os parâmetros para observação dos dados sobre governança nos websites dos municípios pesquisados.

O grupo de informação, Quadro 2, é composto por 10 (dez) grupos de informação e foi utilizado como instrumento para avaliar o nível de divulgação da Governança Pública.

Para mensurar a informação e a interação, foi criada uma escala de valores, Quadro 3. A escala de valores compreende valores de 1 a 5 e vai mensurar a informação disponível (item A) e a interação (Item B). Na interação do usuário com a Administração Pública, foram observadas as ferramentas e os mecanismos disponíveis que permitem uma interação direta no âmbito do grupo de informação, tais como: e-mail, perguntas frequentes, fale conosco, chat, enquetes e redes sociais ${ }^{3}$. A escala de valores é aplicada a cada grupo de informação.

Quadro 2 - Grupos de Informação

\begin{tabular}{|l|l|l|}
\hline \multicolumn{2}{|c|}{$\begin{array}{c}\text { Grupo de } \\
\text { informação }\end{array}$} & \multicolumn{1}{c|}{ Detalhamento } \\
\hline Gl-1 & $\begin{array}{l}\text { Informações } \\
\text { sobre o } \\
\text { município }\end{array}$ & $\begin{array}{l}\text { Estrutura administrativa do } \\
\text { município, organograma, secretárias, } \\
\text { departamentos, gestores e demais } \\
\text { servidores responsáveis por cargos } \\
\text { estratégicos que envolvam interação } \\
\text { com agentes externos, bem como os } \\
\text { meios e mecanismos que viabilizem } \\
\text { a interação entre a administração e a } \\
\text { sociedade. }\end{array}$ \\
\hline Gl-2 & $\begin{array}{l}\text { Serviços } \\
\text { disponíveis }\end{array}$ & $\begin{array}{l}\text { Governo eletrônico e demais } \\
\text { serviços disponibilizados pela } \\
\text { administração: como solicitá-los, } \\
\text { bem como o fluxo de informações } \\
\text { envolvidas em cada serviço, com } \\
\text { identificação dos responsáveis pelo } \\
\text { encaminhamento, documentos } \\
\text { e informações necessários, pré- } \\
\text { requisitos para atendimento e } \\
\text { respostas esperadas em cada fase de } \\
\text { execução. }\end{array}$ \\
\hline
\end{tabular}

3 Rede composta por pessoas ou organizações, conectadas por um ou vários tipos de relações, que partilham valores e objetivos comuns.

\begin{tabular}{|c|c|c|}
\hline \multicolumn{2}{|c|}{$\begin{array}{c}\text { Grupo de } \\
\text { informação }\end{array}$} & \multirow{2}{*}{\begin{tabular}{|l|}
\multicolumn{1}{|c}{ Detalhamento } \\
Disponibilização de legislação \\
municipal e de outras esferas de \\
governo, relevantes no âmbito da \\
Administração Pública Municipal.
\end{tabular}} \\
\hline $\mathrm{Gl}-3$ & Legislação & \\
\hline GI-4 & $\begin{array}{l}\text { Atos de } \\
\text { Pessoal }\end{array}$ & $\begin{array}{l}\text { Informações sobre processos } \\
\text { de contratação de pessoal pela } \\
\text { Administração Pública Municipal, } \\
\text { concursos, processos de seleção, } \\
\text { especificações sobre cargos e forma } \\
\text { de contratação. }\end{array}$ \\
\hline Gl-5 & \begin{tabular}{|l|} 
Processo \\
de planeja- \\
mento (PPA, \\
LDO, LOA) \\
\end{tabular} & $\begin{array}{l}\text { Divulgação de informações sobre } \\
\text { o processo de planejamento } \\
\text { municipal. Etapas e prazos. }\end{array}$ \\
\hline GI-6 & \begin{tabular}{|l|} 
Receitas \\
arrecadadas \\
e recursos \\
repassados \\
ao municí- \\
pio. \\
\end{tabular} & $\begin{array}{l}\text { Informações claras e acessíveis sobre } \\
\text { os recursos obtidos por meio da } \\
\text { arrecadação de tributos municipais e } \\
\text { demais recursos recebidos de outras } \\
\text { esferas de governo. }\end{array}$ \\
\hline Gl-7 & \begin{tabular}{|l|} 
Despesas/ \\
pagamentos
\end{tabular} & $\begin{array}{l}\text { Diz respeito ao comprometimento } \\
\text { com despesas correntes e de capital, } \\
\text { representados pelos pagamentos } \\
\text { efetivados pela Administração } \\
\text { Pública Municipal, detalhadas de } \\
\text { forma que permitam a análise e } \\
\text { acompanhamento dos pagamentos } \\
\text { realizados (função/subfunção, } \\
\text { grupos de despesas, secretarias, } \\
\text { departamentos). }\end{array}$ \\
\hline $\mathrm{Gl}-8$ & \begin{tabular}{|l|} 
Aquisições, \\
contrata- \\
ções e licita- \\
ções.
\end{tabular} & $\begin{array}{l}\text { Compras e contratações de bens } \\
\text { e serviços, inclusive as licitações } \\
\text { em andamento e encerradas, } \\
\text { bem como os resultados de cada } \\
\text { processo, detalhados de forma que } \\
\text { seja possível identificar os licitantes, } \\
\text { preços e itens adquiridos. }\end{array}$ \\
\hline Gl-9 & \begin{tabular}{|l|} 
Contratos, \\
convênios e \\
aditivos.
\end{tabular} & $\begin{array}{l}\text { Contratos e convênios firmados } \\
\text { entre a Administração Pública } \\
\text { Municipal e particular, detalhados } \\
\text { de forma que permitam o } \\
\text { acompanhamento e controle dos } \\
\text { mesmos. }\end{array}$ \\
\hline GI-10 & \begin{tabular}{|l|} 
Informações \\
quantitati- \\
vas e quali- \\
tativas sobre \\
a gestão
\end{tabular} & $\begin{array}{l}\text { Informações sobre secretarias e } \\
\text { serviços que têm maior reflexo } \\
\text { sobre o dia a dia da população como } \\
\text { saúde, educação, turismo, assistência } \\
\text { social, segurança e transportes. }\end{array}$ \\
\hline
\end{tabular}

Fonte: Adaptado dos princípios de governança e da divulgação de dados no setor Público 
Quadro 3 - Escala de valores para mensurar a informação disponível e a interação.

\begin{tabular}{|c|c|c|c|c|c|}
\hline \multirow{4}{*}{ ITEM - A } & \multicolumn{5}{|c|}{ Informação disponível na internet } \\
\hline & 1 ponto & 2 pontos & 3 pontos & 4 pontos & 5 pontos \\
\hline & Nenhuma & Pouca & Alguma & Muita & Toda \\
\hline & $0 \%$ & $1 \%-25 \%$ & $26 \%-50 \%$ & $51 \%-75 \%$ & $76 \%-100 \%$ \\
\hline \multirow{4}{*}{ ITEM - B } & \multicolumn{5}{|c|}{ Informação permite a interação do usuário com a administração } \\
\hline & 1 ponto & 2 pontos & 3 pontos & 4 pontos & 5 pontos \\
\hline & Nenhuma & Pouca & Alguma & Muita & Toda \\
\hline & $0 \%$ & $1 \%-25 \%$ & $26 \%-50 \%$ & $51 \%-75 \%$ & $76 \%-100 \%$ \\
\hline
\end{tabular}

Fonte: Adaptado de Oliveira (2001); Likert (1975)

\section{Análise dos dados e resultados}

Após a pesquisa nos websites institucionais dos municípios, levantou-se o seguinte diagnóstico acerca da divulgação das informações conforme os princípios de governança:

A Tabela 1 apresenta os resultados da análise dos dados disponíveis por município. Para cada município, temos valores totais, média e percentual quanto à disponibilidade da informação (ITEM - A), e a interação (ITEM - B). A pontuação máxima de cada município é 50 pontos, e mínima, 10 pontos para cada item da escala de valores.

O município com maior nível de divulgação dos dados foi o município de Florianópolis, alcançando o to- tal de 38 pontos e a média 4 - Muita informação disponível, abrangendo um percentual de divulgação dos dados entre 51 a $75 \%$.

O menor nível de divulgação dos dados foi apresentado pelos municípios de Paulo Lopes e Governador Celso Ramos com 21 pontos, com índice médio de divulgação 2 - Pouca informação disponível.

O indicador sobre a interação com a Administração Pública Municipal foi 1 - Nenhuma interação. No entanto, ao analisarmos os valores totais, o município de Florianópolis apresentou a maior pontuação total, seguido por Palhoça e São José.

Tabela 1 - Resultados da divulgação dos dados por município.

\begin{tabular}{|c|c|c|c|c|c|c|c|c|}
\hline \multirow{2}{*}{ MUNICÍPIO } & \multicolumn{4}{|c|}{ ITEM - A } & \multicolumn{4}{|c|}{ ITEM - B } \\
\hline & Total & Media & $\%$ & Definição & Total & Media & $\%$ & Definição \\
\hline Florianópolis & 38 & 4 & $51-75$ & Muita & 13 & 1 & 0 & Nenhuma \\
\hline Biguaçu & 37 & 4 & $51-75$ & Muita & 11 & 1 & 0 & Nenhuma \\
\hline Palhoça & 37 & 4 & $51-75$ & Muita & 13 & 1 & 0 & Nenhuma \\
\hline $\begin{array}{l}\text { Santo Amaro } \\
\text { da Imperatriz }\end{array}$ & 36 & 4 & $51-75$ & Muita & 11 & 1 & 0 & Nenhuma \\
\hline Antônio Carlos & 32 & 3 & $26-50$ & Alguma & 11 & 1 & 0 & Nenhuma \\
\hline São José & 32 & 3 & $26-50$ & Alguma & 12 & 1 & 0 & Nenhuma \\
\hline $\begin{array}{l}\text { São Pedro de } \\
\text { Alcântara }\end{array}$ & 25 & 3 & $26-50$ & Alguma & 11 & 1 & 0 & Nenhuma \\
\hline $\begin{array}{l}\text { Governador } \\
\text { Celso Ramos }\end{array}$ & 21 & 2 & $1-25$ & Pouca & 11 & 1 & 0 & Nenhuma \\
\hline Paulo Lopes & 21 & 2 & $1-25$ & Pouca & 11 & 1 & 0 & Nenhuma \\
\hline
\end{tabular}

Fonte: do autor.

Baseado na Figura 2, verificou-se que o grupo de informação com maior nível de divulgação diz respeito à Legislação (GI-3), alcançando a média acima de 4 - Muita informação. Já a menor divulgação de informações é sobre o processo de planejamento municipal (GI-5), com valor pouco acima do mínimo, 1 - Nenhuma informação disponível.
A divulgação dos dados sobre o município (GI-1), receitas arrecadadas e recursos repassados ao município (GI-6) e sobre as aquisições, contratações e licitações (GI8), alcançou uma média 3 , apresentando uma disponibilidade de dados entre 26 a $50 \%$. 
Figura 2 - Resultados da pesquisa por grupo de informação

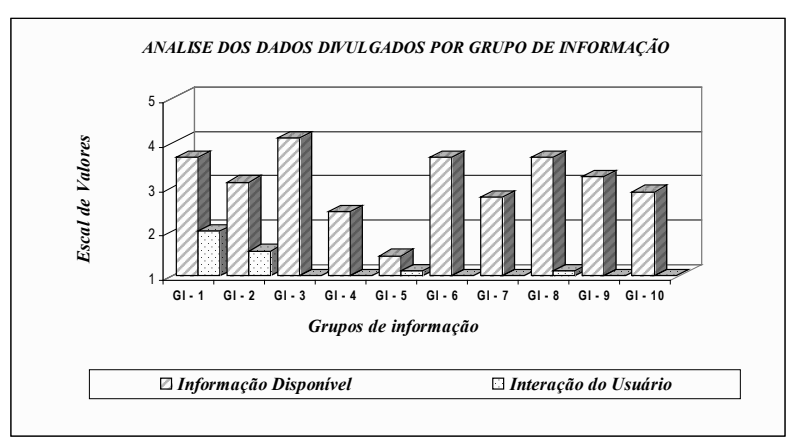

Fonte: do autor.

\section{Conclusão}

Com a realização deste trabalho, procurou-se mensurar a disponibilidade dos dados da Administração Pública na internet, com o objetivo de se identificar o nível de divulgação dos dados da Administração Pública Municipal sob a ótica da Governança Pública.

A partir da pesquisa bibliográfica sobre governança e divulgação dos dados no setor público, foi elaborado um quadro com 10 grupos de informação. Com base nesse quadro e aplicando uma escala de valores, foram observados os dados disponíveis nos websites oficiais dos municípios da microrregião de Florianópolis.

Os principais resultados deste estudo apontam que o nível médio de divulgação da governança nos municípios pesquisados apresentou 31 pontos, numa pontuação máxima de 50, evidenciando que a divulgação dos dados na esfera municipal ficou entre 26 a $50 \%$, classificada como 'alguma informação disponível'. O estudo demonstrou que os municípios ainda apresentam limitações na divulgação dos dados, restringindo a participação da população na gestão pública, no acesso eficiente aos serviços públicos e no entendimento do processo decisório, especialmente sobre o processo de planejamento (GI5), que alcançou o menor nível de divulgação.

A interação dos usuários com a Administração Pública, ponto importante no contexto da governança foi limitada, e os mecanismos e ferramentas de comunicação e de interação disponíveis não apresentam condições para que ocorra troca de informações e de comunicação eficiente com a Administração Pública.

A divulgação de todas as ações governamentais deve ser um dos objetivos da Administração Pública na atualidade. $\mathrm{O}$ acesso livre e transparente aos dados públicos é pré-condição para a participação do cidadão ou de qualquer interessado na gestão da coisa pública e, portanto, para efetividade da Governança Pública. Ao disponibilizar seus dados e instituir canais eficientes de comunicação e de interação, a administração cria um ambiente que contribui para controle social e permite a participação da sociedade nas decisões do município, bem como impede que determinados atos da administração estejam viciados ou mascarados, além de permitir que a população conheça de que forma seus representantes estão conduzindo a máquina administrativa e aplicando os recursos públicos.

A Governança Pública Municipal deve promover e estimular um ambiente social de diálogo, baseado na livre circulação e na troca intensiva de informação, objetivando uma ação conjunta levada a efeito de forma eficaz, transparente e compartilhada pelo Estado, pelas empresas e pela sociedade, a fim de construir consensos que tornem possível desenvolver soluções inovadoras para os problemas sociais e formular políticas públicas que permitam responder equilibradamente ao que a sociedade espera do governo. É dever dos governos prover e estimular a criação de um ambiente que permita o acesso eficiente aos serviços públicos e a participação popular em todo o processo de gestão, desde a formulação das políticas públicas, sua realização, acompanhamento e avaliação.

\section{Referências}

BRASIL. Lei Complementar $n^{\circ} 101$, de 04 de maio de 2000(Lei de Responsabilidade Fiscal). Dispõe sobre normas de finanças públicas voltadas para a responsabilidade na gestão fiscal e dá outras providências. Brasília. Disponível em: <http://www.planalto.gov.br/ccivil_03/Leis/LCP/ Lcp101.htm>. Acesso em: 10 out. 2011.

BRASIL. Constituição (1988). Constituição da República Federativa do Brasil: promulgada em 5 de outubro de 1988. Disponível em: <http://www.planalto.gov.br/ ccivil_03/Constituicao/Constituicao.htm.>. Acesso em: 20 nov. 2011.

BRASIL. Lei $n^{\circ} 12.527$, de 18 de novembro de 2011. Regula o acesso a informações previsto no inciso XXXIII do art. 5o, no inciso II do $\$ 3$ o do art. 37 e no $\$ 2$ o do art. 216 da Constituição Federal; altera a Lei no 8.112, de 11 de dezembro de 1990; revoga a Lei no 11.111 , de 5 de maio de 2005, e dispositivos da Lei no 8.159, de 8 de janeiro de 
1991; e dá outras providências. Disponível em: <http:// www.planalto.gov.br/ccivil_03/_Ato2011-2014/2011/Lei/ L12527.htm>. Acesso em: 28 dez. 2011.

CASTELLS, Manuel. A Sociedade em rede. A era da informação: economia, sociedade e cultura. São Paulo: Paz e Terra, 1999. |v .1

CASTELLS, Manuel. A galáxia da Internet: reflexões sobre a Internet, os negócios e a sociedade. Rio de Janeiro: J. Zahar, 2003.

DINIZ, Eli. Governabilidade, governance e reforma do Estado: considerações sobre o novo paradigma. Revista do Serviço Público, Brasília, ano 47, v. 120, n. 2, p. 5, maio/ ago. 1996.

FIGUEIREDO, N. M. A. Método e metodologia na pesquisa científica. São Caetano do Sul. SP: Difusão. 2004.

GIL, Antônio Carlos. Como elaborar projetos de pesquisa. 4. ed. São Paulo: Atlas, 2002.

INSTITUTO BRASILEIRO DE GOVERNANÇA CORPORATIVA. Código das melhores práticas de governança corporativa. Disponível em: <http://www. ibgc.org.br.>. Acesso em: 07 jul. 2011.

INSTITUTO BRASILEIRO DE GOVERNANÇA CORPORATIVA. Origem da boa governança. Disponível em: <http://www.ibgc.org.br/Secao.aspx?CodSecao=18. Aceso em: 07 jul. 2011.

ÍNDICE DE TRANSPARÊNCIA. Homepage índice de transparência. Disponível em: <http://www. indicedetransparencia.com. $>$. Acesso em: 15 dez. 2011.

INSTITUTO BRASILEIRO DE GEOGRAFIA E ESTATÍSTICA. Cidades. Disponível em: <http://www. ibge.gov.br/cidadesat/link.php?uf=sc.>. Acesso em: 22 nov. 2011.

KISSLER, Leo; HEIDEMANN, Francisco G. Governança pública: novo modelo regulatório para as relações entre Estado, mercado e sociedade? Revista de Administração Pública (RAP), Rio de Janeiro, v. 4. n. 3, maio/jun. 2006.

LÉVY, Pierre. O que é o virtual? São Paulo: Editora 34, 1997. (coleção Trans).

LIKERT, Rensis. A organização humana. São Paulo: Atlas, 1975.
OLIVEIRA, Tânia M. V. de. Escalas de Mensuração de atitudes: Thurstone, Osgood, Stapel, Likert, Guttman, Alpert. Administração On Line, v. 2 n. 2, abr./maio/jun. 2001. Disponível em:< http://www.fecap.br/adm_online/ art22/tania.htm. . Acesso em: 12 nov. 2011.

RAUPP, F. M; BEUREN, I. M. Metodologia de Pesquisa Aplicável às Ciências Sociais. In: BEUREN, Ilse Maria (Org). Como elaborar trabalhos monográficos em Contabilidade: teoria e prática. 3. ed. São Paulo: Atlas, 2009.

SANTOS, Maria Helena de Castro. "Governabilidade, governança e democracia: criação da Capacidade Governativa e Relações Executivo-Legislativo no Brasil Pôs-Constituinte". DADOS - Revista de Ciências Sociais, Rio de Janeiro, v. 40, n. 3, p. 335-376, 1997.

SANT'ANA, Ricardo César Gonçalves. Tecnologia $e$ Gestão Pública Municipal: mensuração da interação com a sociedade. São Paulo: Cultura Acadêmica, 2009.

SILVA, Edna Lúcia da; MENEZES, Estera Muszkat. Metodologia da pesquisa e elaboração de dissertação. 3. ed. rev. atual. Florianópolis: Laboratório de Ensino a Distância da UFSC, 2001. Disponível em: <http:// projetos.inf.ufsc.br/.>. Acesso em: 10 nov. de 2011.

SLOMSKI, Valmor. Controladoria e Governança na Gestão Pública. São Paulo: Atlas, 2009.

STREIT, Rosalvo Ermes. Um modelo baseado em agentes para a análise da governança regulamentar do sistema financeiro. $286 \mathrm{f}$. Tese (Doutorado) - Universidade Federal do Rio Grande do Sul, Escola de Administração. 2006. Disponível em: <http://www.lume.ufrgs.br/bitstream/ handle/10183/7485/000546106.pdf ? sequence $=1>$.. Acesso em: $20 \mathrm{dez} .2011$.

TAKAHASHI, Tadao. Sociedade da informação no Brasil: livro verde. Brasília: Ministério da Ciência e Tecnologia, 2000. Disponível em: <http://www.mct.gov.br/index.php/ content/view/18878.html >. Acesso em: 13 nov. 2011.

VIANA, Evandro. A Governança Corporativa no setor público municipal - um estudo sobre a eficácia da implementação dos princípios de governança nos resultados fiscais. Dissertação (Mestrado) - Faculdade de Economia, Administração e Contabilidade de Ribeirão Preto da Universidade de São Paulo. Ribeirão Preto. 2010. 120f. Disponível em: http://www.teses.usp.br/teses/ disponiveis/96/96133/tde-07012011-094505/pt-br.php. Acesso em: $28 \mathrm{dez} .2011$. 